\title{
Coordinating Three-Level Supply Chain under Disruptions Using Revenue-Sharing Contract with Effort Dependent Demand
}

\author{
Qinghua Pang, Yanli Hou, and Yifei Lv \\ School of Business Administration, Hohai University, Changzhou 213022, China \\ Correspondence should be addressed to Qinghua Pang; pangqh77@126.com
}

Received 27 October 2015; Revised 29 December 2015; Accepted 30 December 2015

Academic Editor: Young Hae Lee

Copyright (C) 2016 Qinghua Pang et al. This is an open access article distributed under the Creative Commons Attribution License, which permits unrestricted use, distribution, and reproduction in any medium, provided the original work is properly cited.

\begin{abstract}
Considering that the market demand is stochastic and dependent on effort, this essay shows that the benchmark revenue-sharing contract could not coordinate a three-level supply chain consisting of one manufacturer, one distributor, and one retailer. By assuming that the retailer himself bears the effort cost, coordination is achieved by implementing revenue-sharing contract based on rebate and penalty policy in one transaction or two transactions of three-level supply chain, and the former is a special case of the latter. When the disruptions induce the changes of the market demand, the revenue-sharing contract could not coordinate the supply chain. To deal with the problem, this essay introduces two forms of improved revenue-sharing contracts which have antidisruption ability. The model of improved revenue-sharing contract is optimized when the market demand is in the additive form with effort dependent demand. Formulas are given to calculate the optimal contract parameters. Finally, this essay demonstrates the accuracy of the model of improved revenue-sharing contract with the help of numerical examples.
\end{abstract}

\section{Introduction}

Modern society is in a period of frequent emergencies, such as the financial crisis that swept the globe world in 2008, the Japanese earthquake in 2011, the bird flu of H7N9 in 2013, and the Tianjin explosion in 2015. These incidents significantly influenced supply chain coordination, resulting in discontinuous supply of raw materials and unavailable transportation facilities as well as significant changes of the market demand. All of the impacts above often cause the coordinated supply chain to be no longer coordinated. Therefore, it is very urgent and necessary to study the ability of the supply chain to cope with the emergencies and develop operation management.

Supply chain contract can improve the ability of the supply chain system to respond to emergencies, which has been recognized by scholars. Qi et al. [1] and Huang et al. [2], respectively, studied the quantity discount contract and the price discount contract to deal with emergencies. Xiao [35] studied how to use the full quantity discount contract and the linear quantity discount contract to deal with emergencies and discussed what to do to improve when manufacturing cost changes.
Zhang et al. [6] and Pang et al. [7] had studied the revenue-sharing contract to deal with emergencies in different situations. Yu et al. [8-11] discussed and improved the buy-back contract, the quantity discount contract, the wholesale price contract, and the revenue-sharing contract, so that the supply chain has an antidisruption ability. Ma and Zhou [12] studied the option contract under disruptions. Zhang and Chen [13] proposed the supplementary contract of unsold goods in the case of VMI. Cao and Lai [14] and Pang [15] studied revenue-sharing contract to respond to emergencies. And their assumptions are different from those of Yu et al. [9]. Hu and Wang [16] discussed the price discount contract to deal with emergencies. Jiang and Cui [17] studied the target rebate contract to deal with emergencies. Qin et al. $[18,19]$ discussed the option contract and the feedback and penalty contract in response to emergencies.

However, the literature above did not take impact of effort on the market demand into account, which is inconsistent with reality. Nowadays, in the increasingly competitive market, with life cycles of products getting shorter, companies need to constantly conduct effort activities to develop in the market, such as increasing advertising investment and designing and manufacturing personalized products. 
The kind of effort behavior seems particularly necessary especially when emergencies cause fluctuations in market demand. Efforts can increase the market demand to some extent $[20,21]$ but also need some cost at the same time. Therefore, the supply chain member who bears all effort cost alone often chooses the effort level which is most beneficial to himself but not to the supply chain coordination [22]. Some scholars proposed the strategy of sharing effort cost [23-27]. However, in many situations like asymmetric information, as effort behavior cannot be effectively supervised and due to the existence of moral hazard, this strategy cannot be implemented. Then, scholars began to pay attention to the situation that one of the supply chain members bears effort cost and various research results were obtained [28-31].

It should be noticed that most of the literatures mentioned above are based on a two-level supply chain. Through literature searching, we have not found the literature that takes effort into account in three-level supply chain. Three-level supply chain is more than the simple superposition of two two-level supply chains. In fact, the supply chain is usually characteristic of three-level structure and above, and possessing its own unique operating pattern. It is equipped with multitransactions, which will be affected more profoundly by disruptions. Therefore, it is significant to study coordination of the three-level supply chain under disruptions.

The existing literatures have a positive effect on the coordination of the supply chain to cope with emergencies. Cachon and Lariviere [32] discussed the strengths and limitations of the revenue-sharing contract in detail. Based on the literature of Cachon and Lariviere [32], Giannoccaro and Pontrandolfo [33] proposed a model based on revenuesharing contract to coordinate a three-level supply chain. van der Rhee et al. [34] discussed the major drawbacks from an implementation point of view and proposed the spanning revenue-sharing contract to coordinate multiechelon supply chains. However, literatures [32-34] ignored the impact of emergencies on supply chain coordination. Although literatures $[6,7,14,15]$ considered the antidisruption ability of revenue-sharing contract, they ignored the influences of effort in supply chain coordination. Literatures [22, 23, 29, 30] take the effort into consideration, but they did not consider the supply chain coordination under the circumstance of emergencies.

Based on the three-level supply chain, this paper studies how to deal with emergencies by revenue-sharing contract with effort dependent demand. This paper focuses on the following three aspects. First of all, it analyzes the impact of effort on the supply chain coordination. It is proposed that the revenue-sharing contract based on the rebate and penalty policy can coordinate the three-level supply chain when the retailer bears the effort cost alone by implementing revenuesharing contract based on rebate and penalty policy in one transaction or two transactions of three-level supply chain. Furthermore, it studies the impact of emergencies on the supply chain coordination and puts forward two forms of the revenue-sharing contracts which have an antidisruption ability so as to improve the capacity of handling emergencies. Finally, based on the hypothesis that the demand and the retail price satisfy an additive form, we optimize the revenue-sharing contract model and give out the method to calculate the optimal parameters (inventory quantity and effort level).

\section{Model Description}

The supply chain introduced in this paper is made up of one manufacturer, one distributor, and one retailer. An upstream member provides products to a downstream member and can meet its order demand. Before the sale season, both the distributor and the retailer have only one chance to buy products. The retailer is in the terminal of the supply chain, so he can better observe the change of the market demand and make more targeted efforts. All members are confronted with neutral risks and information is symmetric among them. Assume that the effort activities, like increasing advertising investment and providing better service and product display, are carried out by the retailer. Furthermore, the retailer bears all effort cost alone. The market demand is assumed to be stochastic and dependent on the effort of the retailer.

Assume $p$ is the sales price of unit product; $c_{i}$ represents supply chain member's marginal unit cost $(i=m, d, r)$ and $c=c_{r}+c_{d}+c_{m} ; w_{i}^{j}$ is the wholesale price that upstream member charges downstream member in $j$ condition $(j=$ $c, d ; i=m, d)$; here, $j=c$ means in the revenue-sharing contract and $j=d$ means in the decentralized supply chain condition; $v$ means salvage value for unsold unit product; $Q$ stands for order quantity; $e$ is the retailer's effort, and $e \geq 0$; $g(e)$ is the retailer's effort cost when his effort is $e$, supposing $g(0)=0$, and $g^{\prime}(e)>0$ and $g^{\prime \prime}(e)>0 ; x$ is the stochastic demand when retailer's effort is $e$, with probability density function $f(x \mid e)$ and differentiable cumulated distribution function $F(x \mid e)$, and $F(x \mid e)$ is continuously differentiable; because the demand is the increasing function of effort, $\partial F(x \mid e) / \partial e<0 ; S(Q, e)$ is the expectation sale quantity and $S(Q, e)=E \min (Q, x)=Q-\int_{0}^{Q} F(x \mid e) d x$, and $\partial S(Q, e) / \partial e>0$; the expectation unsold quantity is $I(Q, e)$, and $I(Q, e)=Q-S(Q, e)$.

Emergencies always result in changes in the size of the market demand. Emergencies may cause an increase in the demand. For example, after "SARS" occurred, the market demand for masks apparently increased. Urgent production and transportation need to be started, which will bring about a certain cost to the manufacturer and the distributor. Assume $\alpha_{i}$ is the increased cost of unit product when emergencies cause an increase in the demand $(i=d, m)$, and $\alpha=\alpha_{d}+\alpha_{m}$; emergencies may also cause a decrease in the demand. For example, after the bird flu occurred, the market demand for poultry like chickens apparently decreased. Supply chain members will bear cost of processing left products. Assume $\beta_{i}$ is the increased cost of unit product when emergencies cause a decrease in the demand $(i=$ $r, d, m)$ and $\beta=\beta_{r}+\beta_{d}+\beta_{m}$.

\section{Coordination Model}

In the three-level supply chain under the revenue-sharing contract, we assume that the manufacturer provides the 
distributor with the revenue-sharing contract $\left(w_{m}^{c}, \phi_{1}\right)$ and the distributor provides the retailer with the revenue-sharing contract $\left(w_{d}^{c}, \phi_{2}\right)$. Considering effort dependent demand, the profit function of the supply chain system can be described as

$$
\begin{aligned}
\prod_{t}(Q, e) & =p S(Q, e)+v I(Q, e)-c Q-g(e) \\
& =(p-v) S(Q, e)-(c-v) Q-g(e) .
\end{aligned}
$$

In the benchmark revenue-sharing contract, the profit function of the retailer can be described as

$$
\begin{aligned}
\prod_{r}^{c}(Q, e)= & \phi_{2}[p S(Q, e)+v I(Q, e)]-c_{r} Q-w_{d}^{c} Q \\
& -g(e) \\
= & \phi_{2}(p-v) S(Q, e)-\left(c_{r}+w_{d}^{c}-\phi_{2} v\right) Q \\
& -g(e) .
\end{aligned}
$$

According to assumptions in this paper, from (1), we can get $\partial \prod_{t}(Q, e) / \partial e=(p-v)(\partial S(Q, e) / \partial e)-g^{\prime}(e)$ and from $(2)$ we can get $\partial \prod_{r}^{c}(Q, e) / \partial e=\phi_{2}(p-v)(\partial S(Q, e) / \partial e)-g^{\prime}(e)$. Then, it can be gotten that $\partial \prod_{r}^{c}(Q, e) / \partial e<\partial \prod_{t}(Q, e) / \partial e$. It means that the effort level of the retailer here is lower than that of the centralized supply chain. That is, considering the effort dependent demand, the traditional revenue-sharing contract cannot coordinate the supply chain. The reason lies in that the retailer bears all the effort cost of supply chain $g(e)$ but only gets partial profit of the whole supply chain. So he will choose the effort level best beneficial to himself but not to the supply chain system. The result is consistent with the literature [22].

In order to make the supply chain remain coordinate, we need to improve the traditional revenue-sharing to make the retailer's optimal effort equal to the supply chain's optimal effort. Here, we propose an improved revenue-sharing contract based on rebate and penalty policy. The rebate and penalty policy, also called target incentive policy, means that given a sales target by the supplier, the retailer will get some reward when he overfulfills the task and vice versa. Because there are two different transaction phases ((manufacturer, distributor) and (distributor, retailer)), we need to consider how to implement this improved contract in three-level supply chain.

3.1. Only Implement the Improved Contract between Retailer and Distributor. This problem can be described as follows: we implement the revenue-sharing contract based on rebate and penalty policy $\left(w_{d}^{c}, \phi_{2}, T, \tau\right)$ between the retailer and the distributor; that is, under the revenue-sharing contract, given the sales target $T$, the reward of unit product for exceeding the target or the punishment of unit product for unfinished goals is $\tau$; and we implement the traditional revenuesharing contract $\left(w_{m}^{c}, \phi_{1}\right)$ between the distributor and the manufacturer. Then, the profit function of the retailer, the distributor, the manufacturer, and the supply chain system can be, respectively, described as

$$
\begin{aligned}
\prod_{r}^{c}(Q, e, \tau) & \\
= & \phi_{2}[p S(Q, e)+v I(Q, e)]+\tau[S(Q, e)-T]-c_{r} Q \\
& -w_{d}^{c} Q-g(e) \\
= & {\left[\phi_{2}(p-v)+\tau\right] S(Q, e)-\left(c_{r}+w_{d}^{c}-\phi_{2} v\right) Q } \\
& -g(e)-\tau T \\
\prod_{d}^{c}(Q, e, \tau) & \\
= & \phi_{1}\left[\left(1-\phi_{2}\right)(p S(Q, e)+v I(Q, e))+w_{d}^{c} Q\right]-c_{d} Q \\
& -w_{m}^{c} Q-\tau[S(Q, e)-T] \\
= & {\left[\phi_{1}\left(1-\phi_{2}\right)(p-v)-\tau\right] S(Q, e) } \\
& -\left[c_{d}+w_{m}^{c}-\phi_{1}\left(1-\phi_{2}\right) v-\phi_{1} w_{d}^{c}\right] Q+\tau T, \\
\prod_{m}^{c} & (Q, e, \tau) \\
= & \left(1-\phi_{1}\right)\left[\left(1-\phi_{2}\right)(p S(Q, e)+v I(Q, e))+w_{d}^{c} Q\right] \\
& +w_{m}^{c} Q-c_{m} Q \\
= & \left(1-\phi_{1}\right)\left(1-\phi_{2}\right)(p-v) S(Q, e) \\
& -\left[c_{m}-w_{m}^{c}-\left(1-\phi_{1}\right)\left(1-\phi_{2}\right) v-\left(1-\phi_{1}\right) w_{d}^{c}\right] Q .
\end{aligned}
$$

Theorem 1. Assuming the contract parameters satisfy (6), the improved revenue-sharing contract based on the rebate and penalty policy can coordinate the three-level supply chain:

$$
\begin{aligned}
\tau= & \left(1-\phi_{2}\right)(p-v), \\
w_{d}^{c}= & c-c_{r}-\left(1-\phi_{2}\right) v, \\
w_{m}^{c}= & {\left[\phi_{1}-\left(1-\phi_{1}\right)\left(1-\phi_{2}\right)\right] c-\phi_{1} c_{r}-c_{d} } \\
& +\left(1-\phi_{1}\right)\left(1-\phi_{2}\right) v .
\end{aligned}
$$

Proof. Take (6) into the profit function of each supply chain member and we can get (7)

$$
\begin{aligned}
\prod_{r}^{c}(Q, e, \tau)= & \prod_{t}(Q, e)-\left(1-\phi_{2}\right)(p-v) T, \\
\prod_{d}^{c}(Q, e)= & -\left(1-\phi_{1}\right)\left(1-\phi_{2}\right)\left[\prod_{t}(Q, e)+g(e)\right] \\
& +\left(1-\phi_{2}\right)(p-v) T, \\
\prod_{m}^{c}(Q, e)= & \left(1-\phi_{1}\right)\left(1-\phi_{2}\right)\left[\prod_{t}(Q, e)+g(e)\right] .
\end{aligned}
$$

From (7), we can get the following:

$$
\begin{aligned}
\frac{\partial \prod_{r}^{c}\left(Q, e^{*}, \tau\right)}{\partial e} & =\frac{\partial \prod_{t}\left(Q, e^{*}\right)}{\partial e} \\
& =(p-v) \frac{\partial S\left(Q, e^{*}\right)}{\partial e}-g^{\prime}\left(e^{*}\right),
\end{aligned}
$$




$$
\begin{aligned}
\frac{\partial \prod_{r}^{c}\left(Q^{*}, e, \tau\right)}{\partial Q} & =\frac{\partial \prod_{d}^{c}\left(Q^{*}, e\right)}{\partial Q}=\frac{\partial \prod_{m}^{c}\left(Q^{*}, e\right)}{\partial Q} \\
& =\frac{\partial \prod_{t}\left(Q^{*}, e\right)}{\partial Q} .
\end{aligned}
$$

According to (8), it can be seen that the optimal effort level of the retailer and the optimal order quantity of supply chain members are equal to those of the supply chain system. Moreover, the profit functions of the supply chain members are all affine functions of the whole supply chain's profit function. So, in this condition, the revenue-sharing contract can coordinate the three-level supply chain.

\subsection{Implement the Improved Contract among Supply Chain} Members. This problem can be described as follows: we implement the revenue-sharing contract based on rebate and penalty policy both between the retailer and the distributor and between the distributor and the manufacturer. That is, under the revenue-sharing contract, suppose the sales target set by the distributor to the retailer is $T_{r}$; the reward of unit product for exceeding the target or the punishment of unit product for unfinished goals is $\tau_{r}$; the sales target set by the manufacturer to the distributor is $T_{d}$; the reward of unit product for exceeding the target or the punishment of unit product for unfinished goals is $\tau_{d}$. Then, the profit function of the retailer, the distributor, the manufacturer, and the supply chain system can be, respectively, described as

$$
\begin{aligned}
& \prod_{r}^{c}\left(Q, e, \tau_{r}\right) \\
& =\phi_{2}[p S(Q, e)+v I(Q, e)]+\tau_{r}\left[S(Q, e)-T_{r}\right]-c_{r} Q \\
& -w_{d}^{c} Q-g(e) \\
& =\left[\phi_{2}(p-v)+\tau_{r}\right] S(Q, e)-\left(c_{r}+w_{d}^{c}-\phi_{2} v\right) Q \\
& -g(e)-\tau_{r} T_{r}, \\
& \prod_{d}^{c}\left(Q, e, \tau_{r}, \tau_{d}\right) \\
& =\phi_{1}\left[\left(1-\phi_{2}\right)(p S(Q, e)+v I(Q, e))+w_{d}^{c} Q\right]-c_{d} Q \\
& -w_{m}^{c} Q-\tau_{r}\left[S(Q, e)-T_{r}\right]+\tau_{d}\left[S(Q, e)-T_{d}\right] \\
& =\left[\phi_{1}\left(1-\phi_{2}\right)(p-v)-\tau_{r}+\tau_{d}\right] S(Q, e) \\
& -\left[c_{d}+w_{m}^{c}-\phi_{1}\left(1-\phi_{2}\right) v-\phi_{1} w_{d}^{c}\right] Q+\tau_{r} T_{r} \\
& -\tau_{d} T_{d} \\
& \prod_{m}^{c}\left(Q, e, \tau_{d}\right) \\
& =\left(1-\phi_{1}\right)\left[\left(1-\phi_{2}\right)(p S(Q, e)+v I(Q, e))+w_{d}^{c} Q\right] \\
& +w_{m}^{c} Q-c_{m} Q-\tau_{d}\left[S(Q, e)-T_{d}\right] \\
& =\left[\left(1-\phi_{1}\right)\left(1-\phi_{2}\right)(p-v)-\tau_{d}\right] S(Q, e)
\end{aligned}
$$

Theorem 2. Assuming the contract parameters satisfy (12), the improved revenue-sharing contract based on the rebate and penalty policy can coordinate the three-level supply chain:

$$
\begin{aligned}
\tau_{r}= & \left(1-\phi_{2}\right)(p-v), \\
w_{d}^{c}= & c-c_{r}-\left(1-\phi_{2}\right) v, \\
w_{m}^{c}= & {\left[\phi_{1}-\left(1-\phi_{1}\right)\left(1-\phi_{2}\right)\right] c-\phi_{1} c_{r}-c_{d} } \\
& +\left(1-\phi_{1}\right)\left(1-\phi_{2}\right) v+\frac{c-v}{p-v} \tau_{d} .
\end{aligned}
$$

Proof. Take (12) into the profit function of each supply chain member and we can get

$$
\begin{aligned}
& \prod_{r}^{c}\left(Q, e, \tau_{r}\right)=\prod_{t}(Q, e)-\left(1-\phi_{2}\right)(p-v) T_{r}, \\
& \prod_{d}^{c}\left(Q, e, \tau_{r}, \tau_{d}\right) \\
& =\left[\frac{\tau_{d}}{p-v}-\left(1-\phi_{1}\right)\left(1-\phi_{2}\right)\right]\left[\prod_{t}(Q, e)+g(e)\right] \\
& \quad+\left(1-\phi_{2}\right)(p-v) T_{r}-\tau_{d} T_{d}, \\
& \prod_{m}^{c}\left(Q, e, \tau_{d}\right) \\
& =-\left[\frac{\tau_{d}}{p-v}-\left(1-\phi_{1}\right)\left(1-\phi_{2}\right)\right]\left[\prod_{t}(Q, e)+g(e)\right] \\
& \quad+\tau_{d} T_{d} .
\end{aligned}
$$

From (13), we can get

$$
\begin{aligned}
\frac{\partial \prod_{r}^{c}\left(Q, e^{*}, \tau_{r}\right)}{\partial e} & =\frac{\partial \prod_{t}\left(Q, e^{*}\right)}{\partial e} \\
& =(p-v) \frac{\partial S\left(Q, e^{*}\right)}{\partial e}-g^{\prime}\left(e^{*}\right), \\
\frac{\partial \prod_{r}^{c}\left(Q^{*}, e, \tau_{r}\right)}{\partial Q} & =\frac{\partial \prod_{d}^{c}\left(Q, e, \tau_{r}, \tau_{d}\right)}{\partial Q} \\
& =\frac{\partial \prod_{m}^{c}\left(Q, e, \tau_{d}\right)}{\partial Q}=\frac{\partial \prod_{t}\left(Q^{*}, e\right)}{\partial Q} .
\end{aligned}
$$

Similarly, according to (14), it can be seen that the optimal effort level of the retailer and the optimal order quantity of supply chain members are equal to those of the supply chain system. Moreover, the profit functions of the supply chain members are all affine functions of the whole supply chain's profit function. So, in this condition, the revenue-sharing contract can coordinate the three-level supply chain.

Specially, if we let $\tau_{d}=0, T_{d}=0$, we can find that (7) is the same as (13). Namely, Section 3.1 is a special case of Section 3.2. 
Theorems 1 and 2 illustrate whether we implement the improved revenue-sharing contract only between the distributor and the retailer or among the supply chain members; when the contract parameters satisfy (6) or (12), the improved revenue-sharing contract can coordinate the three-level supply chain. However, in fact, participation constraint must be met if this contract can be adopted by supply chain members. That is, the profit under this revenue-sharing contract must not be less than that under the decentralized model. Namely, the supply chain members should, respectively, satisfy (1) $\prod_{r}^{c}(Q, e) \geq \prod_{r}^{d}(\mathrm{Q}, e),(2) \prod_{d}^{c}(\mathrm{Q}, e) \geq \prod_{d}^{d}(\mathrm{Q}, e)$, and (3) $\prod_{m}^{c}(Q, e) \geq \prod_{m}^{d}(Q, e)$. Here, the superscript $d$ stands for the decentralized model and $c$ stands for the model of the improved revenue-sharing contract.

\section{Supply Chain Coordination under Disruptions}

4.1. Impact of Emergencies on Supply Chain Coordination. Before sale season for the coordinated supply chain, the supply chain members would make the optimal effort level $e^{*}$ and the optimal order quantity $Q^{*}$ according to the market demand as well as arranging corresponding production and operation activities. However, the disruptions would probably induce unexpected changes of the market demand. Assume that the market demand distribution function changes from $F(x \mid e)$ to $G(x \mid e)$ and the probability density function changes from $f(x \mid e)$ to $g(x \mid e)$. Here, $G(x \mid e)$ is continuously differentiable. The expectation sale quantity under disruptions is $S_{g}(Q, e)=Q-\int_{0}^{Q} G(x \mid e) d x$ and the expectation unsold quantity is $I_{g}(Q, e)=Q-S_{g}(Q, e)$.

After emergencies, the profit function of the supply chain system can be described as

$$
\begin{aligned}
\widetilde{\prod}_{t}(Q, e)= & p S_{g}(Q, e)+v I_{g}(Q, e)-c Q-g(e) \\
& -\left(\alpha_{d}+\alpha_{m}\right)\left(Q-Q^{*}\right)^{+} \\
& -\left(\beta_{r}+\beta_{d}+\beta_{m}\right)\left(Q^{*}-Q\right)^{+} \\
= & (p-v) S_{g}(Q, e)-(c-v) Q-g(e) \\
& -\alpha\left(Q-Q^{*}\right)^{+}-\beta\left(Q^{*}-Q\right)^{+} .
\end{aligned}
$$

Here, $(a, 0)^{+}=\max \{a, 0\}$.

If we use the original revenue-sharing contract based on the rebate and penalty policy to coordinate the supply chain, namely, the contract parameters satisfy (6), the profit function of supply chain members can be, respectively, described as (16); the contract parameters satisfy (12); the profit function of supply chain members can be, respectively, described as (17). Consider

$$
\begin{aligned}
& \widetilde{\prod}_{r}^{c}(Q, e, \tau)=\phi_{2}\left[p S_{g}(Q, e)+v I_{g}(Q, e)\right] \\
& \quad+\tau\left[S_{g}(Q, e)-T\right]-c_{r} Q-w_{d}^{c} Q-g(e)-\beta_{r}\left(Q^{*}\right.
\end{aligned}
$$

$$
\begin{aligned}
& -Q)^{+}=\left[\widetilde{\prod}_{t}(Q, e)+\alpha\left(Q-Q^{*}\right)^{+}\right. \\
& \left.+\beta\left(Q^{*}-Q\right)^{+}\right]-\tau T-\beta_{r}\left(Q^{*}-Q\right)^{+}, \\
& \widetilde{\prod}_{d}^{c}(\mathrm{Q}, e, \tau)=\phi_{1}\left[\left(1-\phi_{2}\right)\left(p S_{g}(\mathrm{Q}, e)+v I_{g}(\mathrm{Q}, e)\right)\right. \\
& \left.+w_{d}^{c} Q\right]-c_{d} Q-w_{m}^{c} Q-\tau\left[S_{g}(Q, e)-T\right]-\alpha_{d}(Q \\
& \left.-Q^{*}\right)^{+}-\beta_{d}\left(Q^{*}-Q\right)^{+}=-\left(1-\phi_{1}\right)\left(1-\phi_{2}\right) \\
& \cdot\left[\widetilde{\prod}_{t}(Q, e)+g(e)+\alpha\left(Q-Q^{*}\right)^{+}\right. \\
& \left.+\beta\left(Q^{*}-Q\right)^{+}\right]+\tau T-\alpha_{d}\left(Q-Q^{*}\right)^{+}-\beta_{d}\left(Q^{*}\right. \\
& -Q)^{+}, \\
& \widetilde{\prod}_{m}^{c}(Q, e, \tau)=\left(1-\phi_{1}\right) \\
& \cdot\left[\left(1-\phi_{2}\right)\left(p S_{g}(Q, e)+v I_{g}(Q, e)\right)+w_{d}^{c} Q\right] \\
& +w_{m}^{c} Q-c_{m} Q-\alpha_{m}\left(Q-Q^{*}\right)^{+}-\beta_{m}\left(Q^{*}-Q\right)^{+} \\
& =\left(1-\phi_{1}\right)\left(1-\phi_{2}\right)\left[\widetilde{\prod}_{t}(Q, e)+g(e)\right. \\
& \left.+\alpha\left(Q-Q^{*}\right)^{+}+\beta\left(Q^{*}-Q\right)^{+}\right]-\alpha_{m}\left(Q-Q^{*}\right)^{+} \\
& -\beta_{m}\left(Q^{*}-Q\right)^{+} \text {, } \\
& \widetilde{\prod}_{r}^{c}(Q, e, \tau)=\phi_{2}\left[p S_{g}(Q, e)+v I_{g}(Q, e)\right] \\
& +\tau_{r}\left[S_{g}(Q, e)-T_{r}\right]-c_{r} Q-w_{d}^{c} Q-g(e)-\beta_{r}\left(Q^{*}\right. \\
& -Q)^{+}=\left[\widetilde{\prod}(Q, e)+\alpha\left(Q-Q^{*}\right)^{+}\right. \\
& \left.+\beta\left(Q^{*}-Q\right)^{+}\right]-\left(1-\phi_{2}\right)(p-v) T_{r}-\beta_{r}\left(Q^{*}\right. \\
& -Q)^{+} \\
& \widetilde{\prod}_{d}^{c}\left(\mathrm{Q}, e, \tau_{r}, \tau_{d}\right)=\phi_{1}\left[\left(1-\phi_{2}\right)(p S(\mathrm{Q}, e)+v I(\mathrm{Q}, e))\right. \\
& \left.+w_{d}^{c} Q\right]-c_{d} Q-w_{m}^{c} Q-\tau_{r}\left[S(Q, e)-T_{r}\right] \\
& +\tau_{d}\left[S(Q, e)-T_{d}\right]-\alpha_{d}\left(Q-Q^{*}\right)^{+}-\beta_{d}\left(Q^{*}\right. \\
& -Q)^{+}=\left[\frac{\tau_{d}}{p-v}-\left(1-\phi_{1}\right)\left(1-\phi_{2}\right)\right]\left[\widetilde{\prod}_{t}(Q, e)\right. \\
& \left.+g(e)+\alpha\left(Q-Q^{*}\right)^{+}+\beta\left(Q^{*}-Q\right)^{+}\right]+\left(1-\phi_{2}\right) \\
& \cdot(p-v) T_{r}-\tau_{d} T_{d}-\alpha_{d}\left(Q-Q^{*}\right)^{+}-\beta_{d}\left(Q^{*}\right. \\
& -Q)^{+},
\end{aligned}
$$




$$
\begin{aligned}
& \widetilde{\prod}_{m}^{c}\left(Q, e, \tau_{d}\right)=\left(1-\phi_{1}\right) \\
& \cdot\left[\left(1-\phi_{2}\right)(p S(Q, e)+v I(Q, e))+w_{d}^{c} Q\right]+w_{m}^{c} Q \\
& -c_{m} Q-\tau_{d}\left[S(Q, e)-T_{d}\right]-\alpha_{m}\left(Q-Q^{*}\right)^{+} \\
& -\beta_{m}\left(Q^{*}-Q\right)^{+}=-\left[\frac{\tau_{d}}{p-v}-\left(1-\phi_{1}\right)\left(1-\phi_{2}\right)\right] \\
& \cdot\left[\widetilde{\prod}_{t}(Q, e)+g(e)+\alpha\left(Q-Q^{*}\right)^{+}\right. \\
& \left.+\beta\left(Q^{*}-Q\right)^{+}\right]-\left(1-\phi_{2}\right)(p-v) T_{r}+\tau_{d} T_{d} \\
& -\alpha_{m}\left(Q-Q^{*}\right)^{+}-\beta_{m}\left(Q^{*}-Q\right)^{+} .
\end{aligned}
$$

It is shown from (16) and (17) that the profit functions of the supply chain members no longer have a linear relationship with the profit function of the supply chain system. Specifically, the profit functions of the supply chain members are no longer affine functions of the supply chain system's profit function. It means the original revenue-sharing contract cannot coordinate the three-level supply chain under disruptions.

4.2. Strategies under Disruptions. In order to make the supply chain remain coordinate under disruptions with effort dependent demand, we need to improve the revenue-sharing contract to equip it with antidisruption ability. Here, we need to consider implementing the improved contract in one transaction process or two transaction processes.

4.2.1. Only Implement the Improved Contract between Distributor and Retailer. The description in this section is same as the description in Section 3.1. Assume the adjusted contract parameters satisfy

$$
\begin{aligned}
\tau= & {\left[\phi_{1}\left(1-\phi_{2}\right)-\phi_{2}\right](p-v), } \\
w_{d}^{c} & =\phi_{1}\left(1-\phi_{2}\right)(c-v)+\phi_{2} v-c_{r}-k_{2} \frac{\left(Q^{*}-Q\right)^{+}}{Q} \beta_{r} \\
& +\phi_{1}\left(1-\phi_{2}\right) \frac{k_{1} \alpha\left(Q-Q^{*}\right)^{+}+k_{2} \beta\left(Q^{*}-Q\right)^{+}}{Q} \\
& -\frac{1-\phi_{1}\left(1-\phi_{2}\right)}{Q} g(e), \\
w_{d}^{c} & =\left[\phi_{2}+\phi_{1}^{2}\left(1-\phi_{2}\right)\right](c-v)-c_{d}+\phi_{1} v-\phi_{1} c_{r} \\
& +\left[\phi_{2}+\phi_{1}^{2}\left(1-\phi_{2}\right)\right] \\
& . \frac{k_{1} \alpha\left(Q-Q^{*}\right)^{+}+k_{2} \beta\left(Q^{*}-Q\right)^{+}}{Q} \\
& +\frac{\phi_{2}-\phi_{1}+\phi_{1}^{2}\left(1-\phi_{2}\right)}{Q} g(e)
\end{aligned}
$$

$$
\begin{aligned}
& -\frac{k_{1} \alpha_{d}\left(Q-Q^{*}\right)^{+}+k_{2} \beta_{d}\left(Q^{*}-Q\right)^{+}}{Q}-k_{2} \phi_{1} \\
& \cdot \frac{\left(Q^{*}-Q\right)^{+}}{Q} \beta_{r} .
\end{aligned}
$$

Here, $k_{1}=\left(Q-Q^{*}\right)^{+} /\left(\left(Q-Q^{*}\right)^{+}+\left(Q^{*}-Q\right)^{+}\right), k_{2}=-\left(Q^{*}-\right.$ $Q)^{+} /\left(\left(Q-Q^{*}\right)^{+}+\left(Q^{*}-Q\right)^{+}\right)$.

Theorem 3. Assuming the contract parameters satisfy (18), the improved revenue-sharing contract can coordinate the threelevel supply chain.

Proof. If market demand rises under disruptions, then $(Q-$ $\left.Q^{*}\right)^{+}=Q-Q^{*},\left(Q^{*}-Q\right)^{+}=0, k_{1}=1$, and $k_{2}=0$; if market demand falls under disruptions, then $\left(Q-Q^{*}\right)^{+}=$ $0,\left(Q^{*}-Q\right)^{+}=Q^{*}-Q, k_{1}=0$, and $k_{2}=-1$. Take (18) into the profit function of each supply chain member after emergencies, and we can get

$$
\begin{aligned}
\widetilde{\prod}_{r}^{c}(Q, e, \tau)= & \phi_{1}\left(1-\phi_{2}\right) \widetilde{\prod}(Q, e) \\
& -\left[\phi_{1}\left(1-\phi_{2}\right)-\phi_{2}\right](p-v) T, \\
\widetilde{\prod}_{d}^{c}(Q, e, \tau)= & \phi_{2} \widetilde{\prod}(Q, e) \\
& +\left[\phi_{1}\left(1-\phi_{2}\right)-\phi_{2}\right](p-v) T, \\
\widetilde{\prod}_{m}^{c}(Q, e, \tau)= & \left(1-\phi_{1}\right)\left(1-\phi_{2}\right) \widetilde{\prod_{t}}(Q, e) .
\end{aligned}
$$

According to (19), it is demonstrated that the profit functions of the retailer, the distributor, and the manufacturer are all affine functions of the whole supply chain's profit function, no matter the market demand rises or falls under disruptions. The optimal effort level and the optimal order quantity of supply chain members are equal to those of the supply chain system. Therefore, when contract parameters satisfy Theorem 3 , the improved revenue-sharing contract can coordinate the three-level supply chain.

4.2.2. Implement the Improved Contract among Supply Chain Members. The description in this section is the same as the description in Section 3.2. Assume the adjusted contract parameters satisfy

$$
\begin{aligned}
\tau_{r} & =\left[\phi_{1}\left(1-\phi_{2}\right)-\phi_{2}\right](p-v), \\
w_{d}^{c} & =c_{r}+\phi_{2} v-\phi_{1}\left(1-\phi_{2}\right)(c-v)-k_{2} \frac{\left(Q^{*}-Q\right)^{+}}{Q} \beta_{r} \\
& +\phi_{1}\left(1-\phi_{2}\right) \frac{k_{1} \alpha\left(Q-Q^{*}\right)^{+}+k_{2} \beta\left(Q^{*}-Q\right)^{+}}{Q} \\
& -\frac{1-\phi_{1}\left(1-\phi_{2}\right)}{Q} g(e),
\end{aligned}
$$




$$
\begin{aligned}
w_{d}^{c} & =\left[\phi_{2}+\phi_{1}^{2}\left(1-\phi_{2}\right)\right](c-v)-c_{d}+\phi_{1} v-\phi_{1} c_{r} \\
& +\left[\phi_{2}+\phi_{1}^{2}\left(1-\phi_{2}\right)\right] \\
& \cdot \frac{k_{1} \alpha\left(Q-Q^{*}\right)^{+}+k_{2} \beta\left(Q^{*}-Q\right)^{+}}{Q} \\
& +\frac{\phi_{2}-\phi_{1}+\phi_{1}^{2}\left(1-\phi_{2}\right)}{Q} g(e) \\
& -\frac{k_{1} \alpha_{d}\left(Q-Q^{*}\right)^{+}+k_{2} \beta_{d}\left(Q^{*}-Q\right)^{+}}{Q}-k_{2} \phi_{1} \\
& \cdot \frac{\left(Q^{*}-Q\right)^{+}}{Q} \beta_{r}+\frac{c-v}{p-v} \tau_{d} .
\end{aligned}
$$

Here, $k_{1}=\left(Q-Q^{*}\right)^{+} /\left(\left(Q-Q^{*}\right)^{+}+\left(Q^{*}-Q\right)^{+}\right), k_{2}=-\left(Q^{*}-\right.$ $Q)^{+} /\left(\left(Q-Q^{*}\right)^{+}+\left(Q^{*}-Q\right)^{+}\right)$.

Theorem 4. Assuming the contract parameters satisfy (20), the improved revenue-sharing contract can coordinate the threelevel supply chain.

Proof. The proof of Theorem 4 is similar to the proof of Theorem 3. If market demand rises under disruptions, then $\left(Q-Q^{*}\right)^{+}=Q-Q^{*},\left(Q^{*}-Q\right)^{+}=0, k_{1}=1$, and $k_{2}=0$; if market demand falls under disruptions, then $\left(Q-Q^{*}\right)^{+}=0$, $\left(Q^{*}-Q\right)^{+}=Q^{*}-Q, k_{1}=0$, and $k_{2}=-1$. Take (18) into the profit function of each supply chain member after emergencies, and we can get

$$
\begin{aligned}
& \widetilde{\prod}_{r}^{c}\left(Q, e, \tau_{r}\right) \\
& =\phi_{1}\left(1-\phi_{2}\right) \widetilde{\prod}_{t}(Q, e) \\
& \quad-\left[\phi_{1}\left(1-\phi_{2}\right)-\phi_{2}\right](p-v) T_{r}, \\
& \widetilde{\prod}_{d}^{c}\left(Q, e, \tau_{r}, \tau_{d}\right) \\
& =\left(\phi_{2}+\frac{\tau_{d}}{p-v}\right) \widetilde{\prod}_{t}(Q, e) \\
& \quad+\left[\phi_{1}\left(1-\phi_{2}\right)-\phi_{2}\right](p-v) T_{r}-\tau_{d} T_{d}, \\
& \widetilde{\prod}_{m}^{c}(Q, e, \tau) \\
& =\left[\left(1-\phi_{1}\right)\left(1-\phi_{2}\right)-\frac{\tau_{d}}{p-v}\right] \widetilde{\prod}_{t}(Q, e)+\tau_{d} T_{d} .
\end{aligned}
$$

According to (21), it is demonstrated that the profit functions of the retailer, the distributor, and the manufacturer are all affine functions of the whole supply chain's profit function, no matter the market demand rises or falls under disruptions. The optimal effort level and the optimal order quantity of supply chain members are equal to those of the supply chain system. Therefore, when contract parameters satisfy Theorem 4, the improved revenue-sharing contract can coordinate the three-level supply chain.

In fact, if we let $\tau_{d}=0, T_{d}=0$, we can find that (18) is the same as (20), and (19) is the same as (21). Namely, Section 4.2.1 also is a special case of Section 4.2.2.

Also, it needs to be pointed out that, under disruptions, participation constraint must be met so that the improved revenue-sharing contract can coordinate the supply chain. Here, it will not be set forth again.

\section{Model Optimization under Disruptions}

From Theorems 3 and 4, we know that the revenue-sharing contract proposed in this paper has an antidisruption ability and can coordinate the supply chain under disruptions. In this section, we discuss how to decide the optimal effort level and the optimal order quantity under disruptions.

With effort dependent demand, we usually use the additive form and the multiplicative form to describe their relationship. In this paper, we adopt the additive form. Assume that the market demand $X(e, \xi)$ is the function of effort $e$ and the random variable $\xi$, and $X(e, \xi)=y(e)+\xi$. Here, $\xi$ and $e$ are independent. $f(\xi)$ and $F(\xi)$ are, respectively, the probability density function and the distribution function of $\xi$; as the market demand is the diminishing marginal function of effort, we assume that $y(e)$ is the monotonically increasing concave function of effort; namely, $y^{\prime}(e)>0$, $y^{\prime \prime}(e) \leq 0$.

Then, the probability density function of stochastic market demand $X(e, \xi)$ can be written as $f(x \mid e)=f(x-$ $y(e))$ and its distribution function can be written as $F(x$ | $e)=F(x-y(e))$. Then, we can further get $S(Q, e)=$ $\mathrm{Q}-\int_{0}^{\mathrm{Q}-y(e)} F(t) d t$. So the profit function of the supply chain system before disruptions can be rewritten as

$$
\begin{aligned}
\prod_{t}(Q, e)= & (p-c) Q-(p-v) \int_{0}^{\mathrm{Q}-y(e)} F(t) d t \\
& -g(e) .
\end{aligned}
$$

Given the effort level $e$, it is easy to know that $\prod_{t}(Q, e)$ is the concave function of $Q$. Hence, the optimal order quantity which meets $\operatorname{Max} \prod_{t}(Q, e)$ should satisfy

$$
Q^{*}=Q^{*}(e)=y(e)+F^{-1}\left(\frac{p-c}{p-v}\right) .
$$

Take (23) into (22), and we can get

$$
\begin{aligned}
\prod_{t}(Q, e)= & (p-c) y(e) \\
& +(p-v) \int_{0}^{F^{-1}((p-c) /(p-v))} t f(t) d t \\
& -g(e) .
\end{aligned}
$$

From (24), we can see that $\prod_{t}(Q, e)$ has only one variable $e$. As $g^{\prime \prime}(e)>0$ and $y^{\prime \prime}(e) \leq 0$, we can get that $\partial^{2} \prod_{t}\left(Q^{*}, e\right) / \partial e^{2}=(p-c) y^{\prime \prime}(e)-g^{\prime \prime}(e)<0$. Hence, 
the optimal effort level $e^{*}$ which meets $\operatorname{Max} \prod_{t}(\mathrm{Q}, e)$ should satisfy

$$
(p-c) y^{\prime}\left(e^{*}\right)-g^{\prime}\left(e^{*}\right)=0 .
$$

Assume that the market demand changes from $X(e, \xi)$ to $X(e, \xi)=y(e)+\xi_{g}$ under disruptions. As market demand may rise or fall, two situations are discussed here.

When market demand falls, namely, $Q<Q^{*}$, (15) can be rewritten as

$$
\begin{aligned}
\widetilde{\prod}_{t}(Q, e)= & (p-v) S_{g}(Q, e)-(c-v) Q-g(e) \\
& -\beta\left(Q^{*}-Q\right) \\
= & (p-c) Q-(p-v) \int_{0}^{Q-y(e)} G(t) d t \\
& -g(e)-\beta\left(Q^{*}-Q\right) .
\end{aligned}
$$

Similar to analysis before disruptions, when market demand falls under disruptions, we can get that the optimal order quantity $\bar{Q}_{1}^{*}$ and the optimal effort level $\bar{e}_{1}^{*}$ of the supply chain system should, respectively, satisfy (27) and (28). Consider

$$
\begin{aligned}
& \bar{Q}_{1}^{*}=\bar{Q}_{1}^{*}(e)=y(e)+G^{-1}\left(\frac{p-c+\beta}{p-v}\right), \\
& (p-c+\beta) y^{\prime}\left(\bar{e}_{1}^{*}\right)-g^{\prime}\left(\bar{e}_{1}^{*}\right)=0 .
\end{aligned}
$$

When market demand rises under disruptions, namely, $Q>Q^{*},(16)$ can be rewritten as

$$
\begin{aligned}
\widetilde{\prod}_{t}(Q, e)= & (p-v) S_{g}(Q, p)-(c-v) Q-g(e) \\
& -\alpha\left(Q-Q^{*}\right) \\
= & (p-c) Q-(p-v) \int_{0}^{Q-y(e)} G(t) d t \\
& -g(e)-\alpha\left(Q-Q^{*}\right) .
\end{aligned}
$$

Similar to analysis before disruptions, when market demand rises under disruptions, we can get that the optimal order quantity $\bar{Q}_{2}^{*}$ and the optimal effort level $\bar{e}_{2}^{*}$ of the supply chain system should, respectively, satisfy (30) and (31). Hence,

$$
\begin{gathered}
\bar{Q}_{2}^{*}=\bar{Q}_{2}^{*}(e)=y(e)+G^{-1}\left(\frac{p-c-\alpha}{p-v}\right), \\
(p-c-\alpha) y^{\prime}\left(\bar{e}_{2}^{*}\right)-g^{\prime}\left(\bar{e}_{2}^{*}\right)=0 .
\end{gathered}
$$

\section{Numerical Analysis}

For convenience of analysis, combining with literature, we make $X(e, \xi)=y(e)+\xi$. Here, $y(e)=e, g(e)=e^{2} / 2$. Assume that $\xi$ has a uniform distribution in the range $[40,100]$ before disruptions and that $\xi_{g}$ has a uniform distribution in the range $[30,80]$ after disruptions. It is easy to know that $f(\xi)=1 / 60, F(\xi)=(\xi-40) / 60$, and $F^{-1}(\xi)=40+60 \xi$ and $g\left(\xi_{g}\right)=1 / 50, G\left(\xi_{g}\right)=\left(\xi_{g}-30\right) / 50$, and $G^{-1}\left(\xi_{g}\right)=30+50 \xi_{g}$. To simplify the analysis, assume $\alpha_{d}=\alpha_{m}=\beta_{r}=\beta_{d}=\beta_{m}=$ $1, v=3, c_{r}=1, c_{d}=2, c_{m}=5, p=35, T=78, \phi_{1}=0.7$, $\phi_{2}=0.4, w_{d}^{d}=19$, and $w_{m}^{d}=11$.

Four situations are considered here. Before emergencies, we adopt the wholesale price contract (decentralized decision-making mode) and the original contract (i.e., the revenue-sharing contract based on the rebate and penalty policy in Section 3). After emergencies, we adopt the original contract and the improved revenue-sharing contract. Here, for convenience of calculation, we suppose that we only implement the improved revenue-sharing contract between the distributor and the retailer. Through calculation, we can get the following:

(1) Adopt the wholesale price contract before emergencies. Through calculation, we can get

$$
\prod_{t}\left(Q^{d}, e^{d}\right)=1897.46, \quad e^{d}=13.62, Q^{d}=87 .
$$

(2) Adopt the original contract before emergencies. Through calculation, we can get

$$
\prod_{t}\left(Q^{*}, e^{*}\right)=2383.72, \quad e^{*}=16.74, Q^{*}=126 .
$$

(3) Adopt the original contract after emergencies. Through calculation, we can get

$$
\widetilde{\prod}_{t}\left(Q^{*}, e^{*}\right)=2041.37, \quad \bar{e}^{*}=14.28, \bar{Q}^{*}=93 .
$$

(4) Adopt the improved revenue-sharing contract after emergencies. Through calculation, we can get

$$
\widetilde{\prod}_{t}\left(Q^{*}, e^{*}\right)=2231.59, \quad \bar{e}^{*}=17.78, \bar{Q}^{*}=119 .
$$

Parameters of the supply chain system in different situations are shown as Table 1.

Table 1 indicates that, before emergencies, the revenuesharing contract proposed in this paper based on the rebate and penalty policy can effectively motivate the retailer to improve his effort level and the order quantity, so that the profit of the supply chain system can rise apparently. That is to say, this contract is superior to the wholesale price contract.

From Table 1, we can also observe that emergencies cause market demand to decrease. So the profit of the supply chain system is less than that before emergencies with the original contract whether it adopts the original contract or the improved contract. After emergencies, as the improved contract has an antidisruption ability and can coordinate the supply chain, we can find that the order quantity and effort level increase compared with the original and the improved contract. Hence, more profit can be obtained.

It is known that the profit distribution of the supply chain members would be affected directly by the profit of the supply chain system. So when the profit of the supply chain system has been improved, the profit of supply chain members will 
TABLE 1: Parameters of supply chain in different modes with effort dependent demand.

\begin{tabular}{lcccc}
\hline & $\begin{array}{c}\text { Without disruptions, with demand satisfying } F(x \mid e) \\
\text { Wholesale price } \\
\text { contract }\end{array}$ & Original contract & \multicolumn{2}{c}{ Under disruptions, with demand satisfying $G(x \mid e)$} \\
& 87 & 126 & Original contract & Improved contract \\
\hline Optimal order quantity $Q^{*}$ & 13.62 & 16.74 & 93 & 119 \\
Optimal effort level $e^{*}$ & 1897.46 & 2383.72 & 14.28 & 17.78 \\
Entire profit $\prod$ & & & 2041.37 & 2231.59 \\
\hline
\end{tabular}

also be improved accordingly. Of course, the distribution of profits among supply chain members is affected by contract parameters. Their bargaining ability and the influence of their status in the supply chain matter. Therefore, participation constraints of supply chain members should be met if the contract can work out in reality. That is to say, values of contract parameters also need to be limited.

\section{Conclusions}

The disruptions will impart great effects on the market demand while effort is the main factor which influences the market demand. How to deal with the disruptions with effort dependent demand is what we must pay attention to in the research of the supply chain contract. In this paper, with stochastic and effort dependent demand, we study the impact of disruptions on the coordination of the revenuesharing contract in the three-level supply chain and get some conclusions as follows:

(1) With the effort dependent demand, the traditional revenue-sharing contract cannot coordinate the supply chain. The reason lies in that the retailer bears all the effort cost but only gets partial profit. Supply chain coordination was achieved by implementing revenuesharing contract based on rebate and penalty policy in one transaction or two transactions of three-level supply chain, and the former is a special case of the latter.

(2) After emergencies, the market demand often changes. The original revenue-sharing contract cannot coordinate the supply chain because the market demand's changes often result in additional costs (such as emergency production costs, logistics costs, and residual product processing fees), which causes the coordinated supply chain to no longer coordinate. In this paper, we make a further adjustment to the original contract. The new contract has an antidisruption ability and can recoordinate the supply chain system.

(3) Considering that the market demand and the effort satisfy the addictive form, this paper gives the method to determine the optimal order quantity and the optimal effort, which can provide the decision makers of the supply chain with decision support.

It also should be noticed that this research is carried out in the neutral risk and symmetrical information condition. So the next step is to carry out the research in the more complex condition. For instance, supply chain members have decision preference. In addition, in this paper, the retailer bears all the effort cost. In the following step, the distributor and the manufacturer can be considered to bear the effort cost.

\section{Conflict of Interests}

The authors declare that there is no conflict of interests regarding the publication of this paper.

\section{Acknowledgment}

This research was supported by the Fundamental Research Funds for the Central Universities (nos. 2015B24014, 2012B13914, and 2013B30714).

\section{References}

[1] X. Qi, J. F. Bard, and G. Yu, "Supply chain coordination with demand disruptions," Omega, vol. 32, no. 4, pp. 301-312, 2004.

[2] C. C. Huang, G. Yub, S. Wangc, and X. Wangd, "Disruption management for supply chain coordination with exponential demand function," Acta Mathematica Scientia, vol. 26, no. 4, pp. 655-669, 2006.

[3] T. Xiao, X. Qi, and G. Yu, "Coordination of supply chain after demand disruptions when retailers compete," International Journal of Production Economics, vol. 109, no. 1-2, pp. 162-179, 2007.

[4] T. J. Xiao and X. T. Qi, "Price competition, cost and demand disruptions and coordination of a supply chain with one manufacturer and two competing retailers," Omega, vol. 36, no. 5, pp. 741-753, 2008.

[5] K. Chen and T. Xiao, "Demand disruption and coordination of the supply chain with a dominant retailer," European Journal of Operational Research, vol. 197, no. 1, pp. 225-234, 2009.

[6] W.-G. Zhang, J. Fu, H. Li, and W. Xu, "Coordination of supply chain with a revenue-sharing contract under demand disruptions when retailers compete," International Journal of Production Economics, vol. 138, no. 1, pp. 68-75, 2012.

[7] Q. H. Pang, Y. E. Chen, and Y. L. Hu, "Three-level supply chain coordination under disruptions based on revenue-sharing contract with price dependent demand," Discrete Dynamics in Nature and Society, vol. 2014, Article ID 464612, 11 pages, 2014.

[8] H. Yu, J. Chen, and G. Yu, "How to coordinate supply chain under disruptions," Systems Engineering-Theory \& Practice, vol. 25, no. 7, pp. 9-16, 2005.

[9] H. Yu, J. Chen, and G. Yu, "Managing wholesale price contract in the supply chain under disruptions," System Engineering Theory \& Practice, vol. 26, no. 8, pp. 31-37, 2006.

[10] H. Yu, J. Chen, and G. Yu, "Supply chain coordination under disruptions with buy back contract," Systems EngineeringTheory \& Practice, vol. 25, no. 8, pp. 38-43, 2005. 
[11] H. Yu and J. Chen, "Response to the disruption of supply chain with price-depended demand," System Engineering Theory \& Practice, vol. 27, no. 3, pp. 36-41, 2007.

[12] C. Ma and Y. W. Zhou, "Supply chain coordination under disruptions by adjusting option contracts," Journal of Hefei University of Technology, vol. 32, no. 3, pp. 430-434, 2009.

[13] J. L. Zhang and J. Chen, "Vender manage inventory under disruption," Chinese Journal of Management Science, vol. 16, no. 5, pp. 71-76, 2008.

[14] E. B. Cao and M. Y. Lai, "Supply chain coordination under disruptions with revenue sharing contract," Journal of Wuhan University of Science and Technology, vol. 30, no. 5, pp. 557-560, 2007.

[15] Q. H. Pang, "Three-level supply chain coordination under disruption with revenue-sharing contract," Chinese Journal of Management Science, vol. 18, no. 8, pp. 101-106, 2010.

[16] J. S. Hu and H. Wang, "The price discount contract analysis of three-level supply chain under disruption," Chinese Journal of Management Science, vol. 15, no. 3, pp. 103-107, 2007.

[17] L. N. Jiang and W. T. Cui, "Supply chain coordination under target rebate contract with demand disruption," Operations Research and Management Science, vol. 21, no. 2, pp. 8-13, 2012.

[18] Y. H. Qin and X. Y. Cao, "Option contracts under disruptions for supply chain coordination," Forecasting, vol. 31, no. 1, pp. 60-64, 2012.

[19] Y. H. Qin and X. Y. Cao, "The impact of emergencies on the closed-loop supply chain coordination under rebate and penalty contracts," Journal of Industrial Engineering and Engineering Management, vol. 26, no. 3, pp. 96-101, 2012.

[20] Y. He, Q.-L. Wu, and L.-D. Zhao, "Quantity flexibility contract with effort and price-dependent demand," Systems Engineering and Electronics, vol. 29, no. 12, pp. 2056-2059, 2007.

[21] T. A. Taylor, "Supply chain coordination under channel rebates with sales effort effects," Management Science, vol. 48, no. 8, pp. 992-1007, 2002.

[22] G. P. Cachon, "Supply chain coordination with contracts," in Handbooks in Operations Research and Management Science: Supply Chain Management, North-Holland, Elsevier Science, Amsterdam, The Netherlands, 2000.

[23] Y. He, X. Zhao, L. D. Zhao, and J. He, "Coordinating a supply chain with effort and price dependent stochastic demand," Applied Mathematical Modelling, vol. 33, no. 6, pp. 2777-2790, 2009.

[24] B. Y. Hu and X. Y. Wang, "The study on collection and pricing for closed-loop supply chain with retailer and the third party collecting," Journal of Industrial Engineering and Engineering Management, vol. 19, no. 2, pp. 35-39, 2010.

[25] D. G. Qu and Y. J. Guo, "Coordination of supply chain with hybrid distribution channels when retailer's demand relies on its sales effort," Chinese Journal of Management Science, vol. 21, no. 3, pp. 19-23, 2008.

[26] Z. Xu, D.-L. Zhu, and W.-G. Zhu, "Supply chain coordination under buy-back contract with sales effort effects," System Engineering Theory \& Practice, vol. 28, no. 4, pp. 1-11, 2008.

[27] G. Tian, B. H. Guo, J. C. Zhuang, and J. Q. Luo, "Response to the disruption of supply chain under revenue-sharing contract with effort dependent demand," Systems Engineering, vol. 33, no. 2, pp. 94-99, 2015.

[28] H. Krishnan, R. Kapuscinski, and D. A. Butz, "Coordinating contracts for decentralized supply chains with retailer promotional effort," Management Science, vol. 50, no. 1, pp. 48-63, 2004.
[29] Q. H. Pang, H. Jiang, Y. M. Hou, and Y. Luo, "Supply chain coordination under revenue-sharing contract with sales effort dependent demand," Journal of Systems \& Management, vol. 22, no. 3, pp. 371-378, 2013.

[30] Q. H. Pang, X. Y. Wu, M. L. Tan, and X. Y. Cao, "Supply chain coordination using revenue-sharing contract with distributor's effort dependent demand," International Journal of Simulation Modelling, vol. 14, no. 2, pp. 335-348, 2015.

[31] H. J. Zhang, X. Gan, and M. Y. Lai, "Coordination of closed-loop supply chain with the optimal price and recycle effort incentive contract," Journal of Systems Engineering, vol. 30, no. 2, pp. 201209, 2015.

[32] G. P. Cachon and M. A. Lariviere, "Supply chain coordination with revenue-sharing contracts: strengths and limitations," Management Science, vol. 51, no. 1, pp. 30-44, 2005.

[33] I. Giannoccaro and P. Pontrandolfo, "Supply chain coordination by revenue sharing contracts," International Journal of Production Economics, vol. 89, no. 2, pp. 131-139, 2004.

[34] B. van der Rhee, J. A. A. van der Veen, V. Venugopal, and V. R. Nalla, "A new revenue-sharing mechanism for coordinating multi-echelon supply chain," Operations Research Letters, vol. 38, no. 3, pp. 296-301, 2010. 


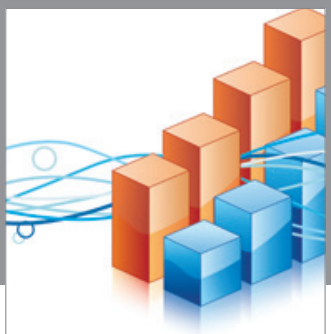

Advances in

Operations Research

vatem alat4

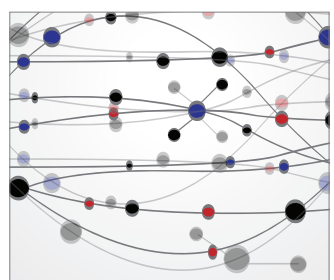

\section{The Scientific} World Journal
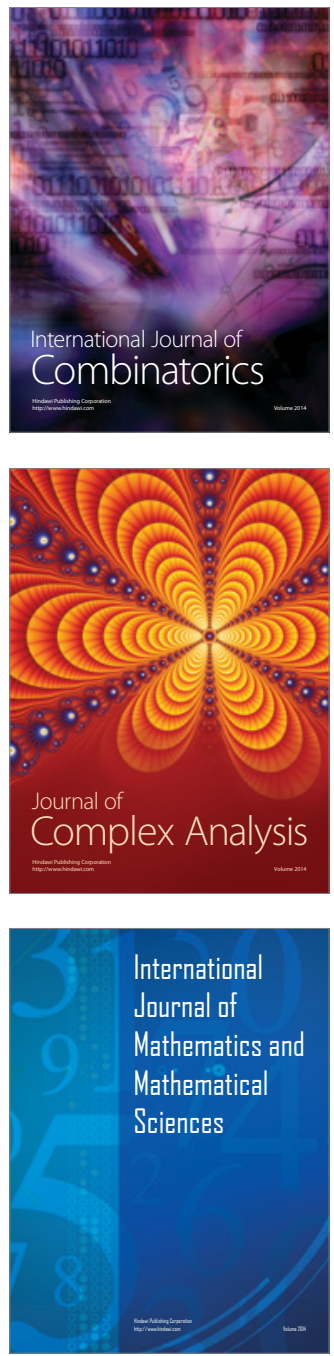
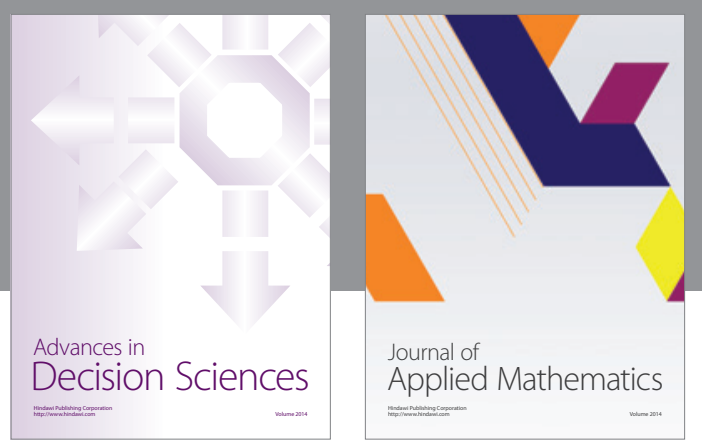

Algebra

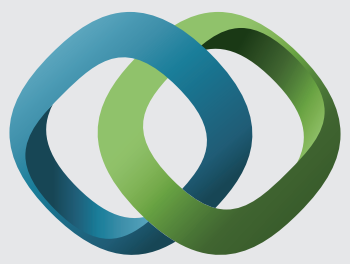

\section{Hindawi}

Submit your manuscripts at

http://www.hindawi.com
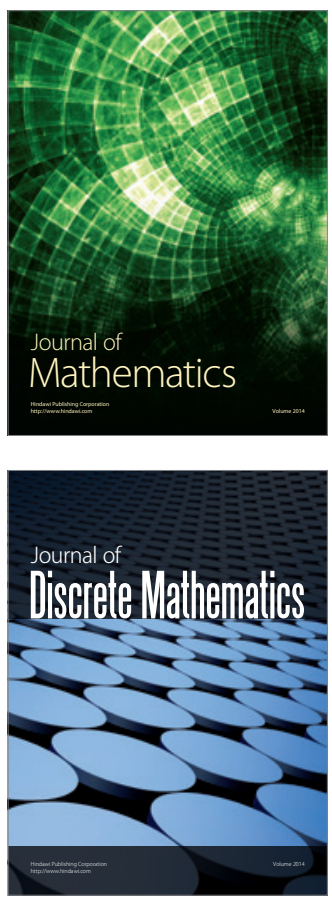

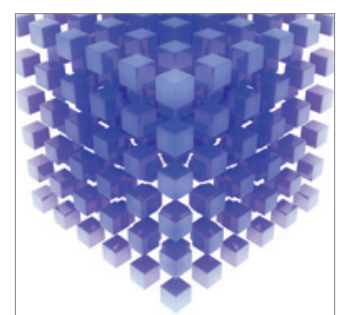

Mathematical Problems in Engineering
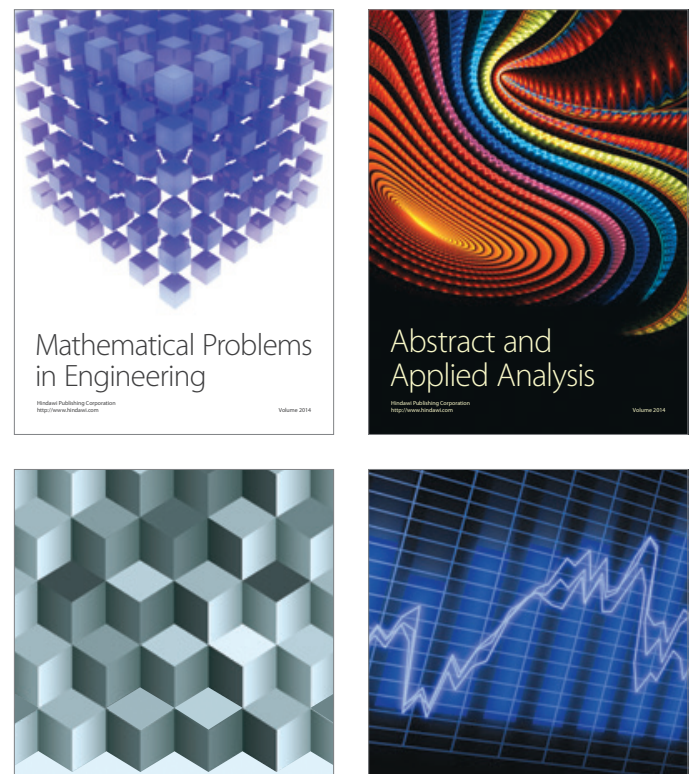

Journal of

Function Spaces

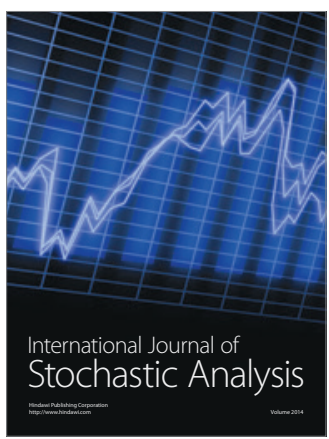

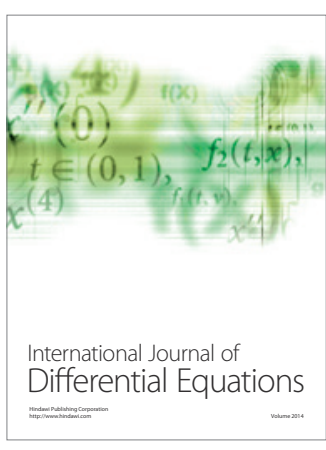
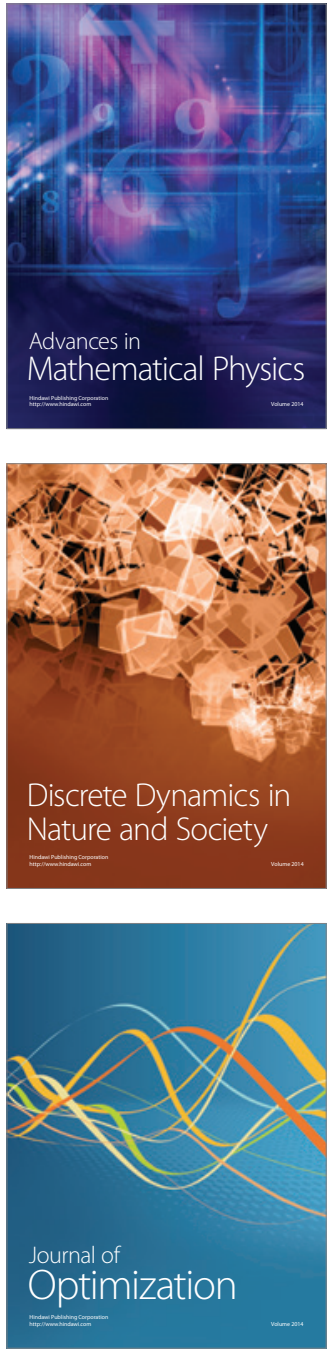